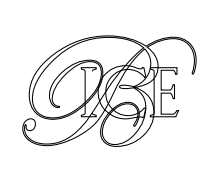

\title{
LA BALANZA COMERCIAL AGROALIMENTARIA EN 2017
}

En este artículo se analiza la evolución de los principales sectores y mercados agrarios durante el año 2017, así como los factores más importantes que determinan el comportamiento de nuestra balanza agroalimentaria. Se ha incluido el análisis sectorial de los productos de los veinticuatro primeros capítulos del arancel.

Palabras clave: importaciones, exportaciones, comercio exterior, agricultura, España, 2017. Clasificación JEL: Q10, Q17.

\section{Evolución general}

De acuerdo con los datos de comercio exterior (Cuadro 1), la balanza comercial agroalimentaria, que comprende los 24 primeros capítulos del arancel, ha registrado en 2017 un superávit de más de 11.622 millones de euros y una ratio de cobertura de 132,4 por 100. La balanza ha contado con un saldo positivo desde el año 2003, y el superávit en 2017 es el mayor valor registrado desde aquel año. La crisis económica no ha impedido que se mantenga la voluntad exportadora de nuestro sector agroalimentario; incluso la ha aumentado. En el Gráfico 1 también se puede observar esta

\footnotetext{
*Ministerio de Industria, Comercio y Turismo.

Versión de octubre de 2018.

Por limitaciones de espacio no se ha podido incluir el análisis sectorial de todos los productos de los veinticuatro primeros capítulos del arancel, sino únicamente los cuadros relativos a su comercio exterior. La versión completa de la balanza agroalimentaria correspondiente a 2017 se encuentra en: http://www.comercio.gob.es/esES/comercio-exterior/informacion-sectorial/agroalimentarios/ estadisticas/Paginas/estadisticas.aspx
}

evolución positiva, con un aumento de la divergencia entre las exportaciones y las importaciones a partir de 2007, que da lugar a un aumento progresivo del saldo.

El peso del comercio exterior de productos agroalimentarios sobre el total de bienes también muestra máximos en los diez últimos años, tanto en exportaciones como en importaciones, si bien en el último año ha disminuido ligeramente.

Durante 2017 han sucedido los siguientes hechos relevantes relacionados con el comercio exterior de productos agroalimentarios:

- Desde el 10 de octubre de 2016 se aplica provisionalmente el Acuerdo de Asociación Económica con la Comunidad para el Desarrollo de África Meridional (EPA SADC), para los países de la Unión Aduanera de África Meridional (SACU), esto es, con Sudáfrica, Botsuana, Lesotho, Namibia y Suazilandia (Mozambique lo $D$ 
CUADRO 1

EVOLUCIÓN DEL COMERCIO EXTERIOR ESPAÑOL DE PRODUCTOS AGROALIMENTARIOS

(Miles de euros)

\begin{tabular}{|c|c|c|c|c|c|c|}
\hline Año & Exportación & Importación & Saldo & Cobertura (\%) & \multicolumn{2}{|c|}{ E sobre el total de mercancías } \\
\hline 2003 & 21.589 .711 & 18.963 .570 & 2.626 .141 & 113,8 & 15,6 & 10,2 \\
2004 & 21.953 .570 & 20.391 .814 & 1.561 .756 & 107,7 & 14,9 & 9,8 \\
2005 & 22.569 .690 & 22.088 .969 & 480.720 & 102,2 & 14,6 & 9,5 \\
2006 & 23.883 .309 & 22.697 .096 & 1.186 .213 & 105,2 & 14,0 & 8,6 \\
2007 & 25.861 .548 & 25.530 .201 & 331.346 & 101,3 & 14,0 & 9,0 \\
2008 & 27.811 .138 & 26.912 .110 & 899.028 & 103,3 & 14,7 & 9,5 \\
2009 & 26.520 .841 & 23.888 .612 & 2.632 .230 & 111,0 & 16,6 & 11,6 \\
2010 & 29.100 .551 & 25.753 .433 & 3.347 .118 & 113,0 & 15,6 & 10,7 \\
2011 & 32.168 .087 & 28.357 .730 & 3.810 .356 & 113,4 & 14,9 & 10,8 \\
2012 & 35.628 .140 & 29.225 .268 & 6.402 .872 & 121,9 & 15,8 & 11,3 \\
2013 & 37.195 .596 & 28.814 .872 & 8.380 .724 & 129,1 & 15,8 & 11,4 \\
2014 & 38.687 .873 & 29.636 .446 & 9.051 .427 & 130,5 & 16,1 & 11,2 \\
2015 & 42.057 .749 & 32.293 .044 & 9.764 .705 & 130,2 & 16,8 & 11,8 \\
2016 & 44.613 .193 & 33.422 .076 & 11.191 .117 & 133,5 & 17,4 & 12,2 \\
2017 & 47.498 .616 & 35.876 .946 & 11.621 .670 & 132,4 & 17,1 & 11,9 \\
\hline Los datos correspondientes a 2017 son provisionales. & & & & \\
Fuente: elaboración propia con datos del Departamento de Aduanas e Impuestos Especiales. & \\
\hline
\end{tabular}

hace desde el 4 de febrero de 2018). Este acuerdo armoniza el arancel común de SACU con respecto a la UE, mejora la liberalización recíproca con Sudáfrica en relación con el Acuerdo sobre Comercio, Desarrollo y Cooperación (TDCA), además de que extiende las concesiones de Sudáfrica a la UE y a los demás países del SACU (estos países continúan beneficiándose de la liberalización total sin contingentes en el acceso a la Unión Europea).

- Desde el 15 de diciembre de 2016 se aplica provisionalmente el Acuerdo Preliminar de Asociación Económica (EPA interino) entre la UE y Ghana. Por parte de la UE, se liberaliza todo el comercio de Ghana excepto armas, algo que ya se aplicaba antes de esa fecha por tratarse de un país menos adelantado (régimen «todo menos armas», EBA). Por parte, hay una lista de concesiones de productos originarios de la UE.

- Desde el 1 de enero de 2017 se aplican provisionalmente las concesiones recíprocas entre la UE y Ecuador como consecuencia de la adhesión de dicho país al Acuerdo Comercial con países de la Comunidad Andina (Colombia y Perú).

- En el mes de febrero de 2017 se notificó a la Organización Internacional de Epizootias (OIE) un brote de gripe aviar altamente patógena en explotaciones de patos situadas en Gerona y Barcelona. Esta situación se notificó a la Organización Internacional de Epizootias (OIE) y se tomaron medidas para evitar la propagación de la enfermedad. Pasados tres meses desde la aplicación de dichas medidas, y dado que no se detectó un nuevo foco, España cumplió las condiciones establecidas en la OIE y volvió a ser $\triangleright$ 


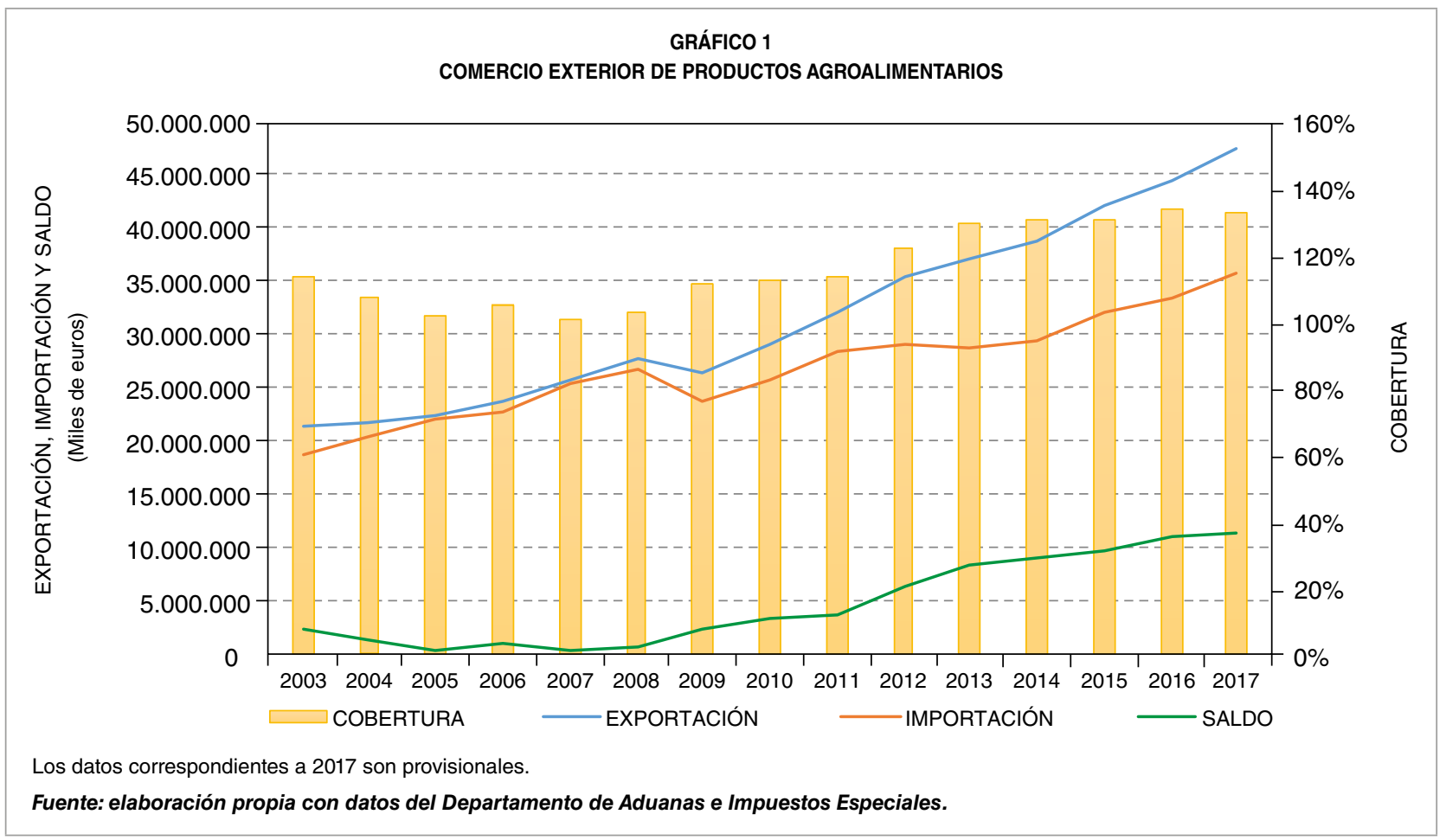

considerado un área libre de gripe aviar desde el día 2 de junio de 2017.

Esta situación tuvo como consecuencia el cierre de las exportaciones procedentes de España durante esos meses y, en algunos casos, la reapertura se ha dilatado más tiempo del que recomienda la OIE, como es el caso de Sudáfrica.

- La exportación de frutas españolas se ha visto afectada desde el 1 de julio de 2017, a raíz de la introducción de medidas sanitarias y fitosanitarias por parte de países que son miembros de la Unión Económica Euroasiática, en particular de Bielorrusia.

- Desde el 21 de septiembre de 2017 se aplica el Acuerdo Económico y Comercial Global (CETA) entre la UE y Canadá, que incluye las concesiones comerciales recíprocas entre las partes del acuerdo.

- Desde el 1 de octubre de 2017 se aplican concesiones autónomas a Ucrania para diversos productos alimenticios, en forma de contingentes arancelarios.

- Durante 2017 se han negociado con las autoridades sanitarias de terceros países las condiciones de acceso de productos agroalimentarios, y ya se puede exportar jamón con hueso y despojos de porcino a India, y ovejas y cabras a Libia.

- La certificación halal se está convirtiendo en un requisito imprescindible para acceder a mercados de mayoría musulmana. En este sentido, en 2017 el Departamento de Desarrollo Islámico de Malasia-Jakim ha vuelto a reconocer a una entidad española como organismo de certificación halal, facilitando así la exportación de productos españoles acreditados halal a Malasia.

- Argelia continúa con su política restrictiva a las importaciones de terceros países. En el año 2017 realizó restricciones a doce productos agroalimentarios: carne de $\triangle$ 
bovino, quesos, concentrado de tomate, limones frescos, manzanas, bananas, maíz, cebada, ajos, torta de soja, polifosfatos para alimento del ganado y concentrado mineral vitaminado.

- Transcurridos más de tres años desde que Rusia aplicase un embargo frente a las importaciones de productos agroalimentarios de la UE, en términos generales, el sector exportador en España ha sabido adaptarse a la nueva coyuntura, intensificando y diversificando su actividad exportadora hacia otros destinos, en especial de frutas y hortalizas. La decisión oficial de prorrogar hasta el 31 de diciembre de 2019 el embargo ruso a los alimentos perecederos procedentes de la Unión Europea es una noticia que complica la situación de las exportaciones españolas de productos agroalimentarios. De forma colateral, el embargo ruso está afectando negativamente a nuestros envíos a Bielorrusia.

En octubre de 2017 Rusia amplía la lista de productos sometidos a embargo, incluyendo cerdos vivos, despojos comestibles, tocino y otras grasas animales.

- Tras la decisión del Reino Unido de salir de la Unión Europea, de acuerdo con el resultado del referéndum celebrado el 23 de junio de 2016, se abre un periodo de incertidumbre en un mercado tan importante para España, que dentro de la UE se basa en el principio de libre circulación de mercancías y fuera de la UE dependerá del resultado de las negociaciones sobre las relaciones comerciales futuras, principalmente bilaterales, pero también en otros ámbitos, como los compromisos de la OMC.
Las exportaciones agroalimentarias (Cuadro 2) supusieron, en 2017, 47.499 millones de euros y 34.492.838 toneladas. En relación con la exportación total de bienes (277.126 millones de euros), las exportaciones agroalimentarias significaron el 17,1 por 100 , cifra muy similar a la participación del año 2016 (17,4 por 100).

Con respecto al año 2016, se ha producido un aumento en valor de un 6,5 por 100 (2.885 millones de euros) y en volumen del 2,8 por 100 (937.832 toneladas).

En volumen, hay nueve capítulos (uno más que en 2016 e igual que en 2015) que superan el millón de toneladas de exportación y suponen el 83,2 por 100 del total exportado. Por orden de importancia son los siguientes: capítulos 8 (frutas y frutos sin conservar), 7 (legumbres y hortalizas sin conservar), 22 (bebidas), 20 (conservas y zumos vegetales), 2 (carne y despojos comestibles), 15 (grasas y aceites animales o vegetales), 23 (residuos de la industria alimentaria), 12 (semillas oleaginosas y plantas industriales) y 10 (cereales).

En cuanto al valor, once capítulos (igual que en 2016 y 2015) han superado los 1.000 millones de euros, suponiendo el 86,8 por 100 del total. Por orden de importancia son los siguientes: capítulos 8 (frutas y frutos sin conservar), 7 (legumbres y hortalizas sin conservar), 2 (carne y despojos comestibles), 15 (grasas y aceites animales o vegetales), 22 (bebidas), 3 (pescados, crustáceos, moluscos), 20 (conservas vegetales y zumos), 19 (productos a base de cereales), 21 (preparaciones alimenticias diversas), 16 (conservas de carne o de pescado) y 4 (leche y productos lácteos y huevos).

La subida del volumen de las exportaciones se ha debido principalmente a los capítulos 8 (frutas y frutos sin conservar), 10 (cereales), 20 (conservas vegetales y zumos), 22 (bebidas), 15 (grasas y aceites animales o vegetales) y $\triangleright$ 


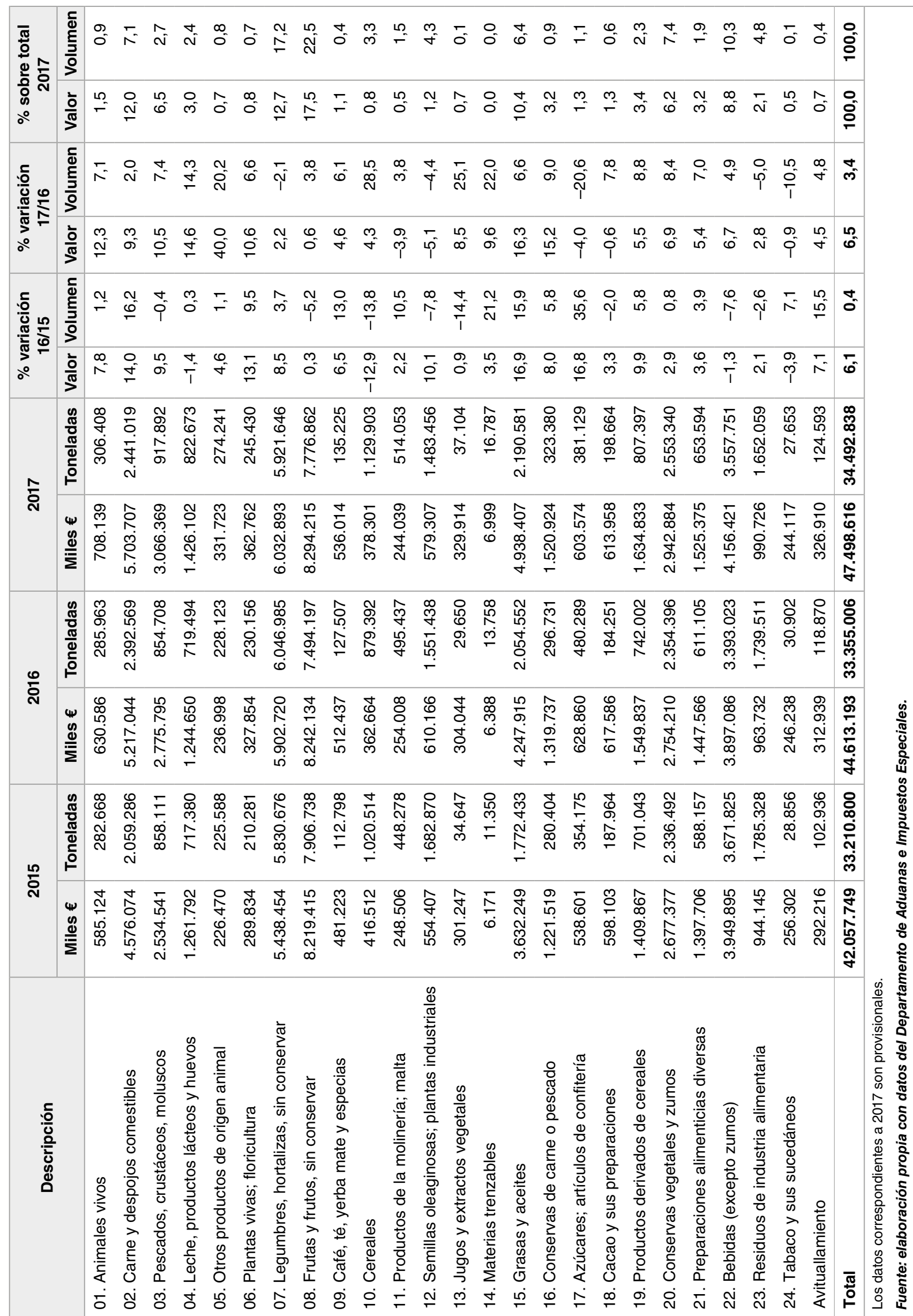


4 (leche y productos lácteos y huevos), todos ellos con aumentos superiores a 100.000 toneladas. Proporcionalmente, destacan en volumen los incrementos de los capítulos 10 (cereales), 13 (jugos y extractos vegetales), 14 (materias trenzables), 5 (otros productos de origen animal) y 4 (leche, productos lácteos y huevos), cada uno con un aumento superior al 10 por 100. Por otro lado, han disminuido las exportaciones en más de un 10 por 100 los capítulos 17 (azúcares y artículos de confitería) y 24 (tabaco y sus sucedáneos). Otros capítulos con reducción de las exportaciones son el 23 (residuos de la industria alimentaria), el 12 (semillas oleaginosas y plantas industriales) y el 7 (legumbres y hortalizas sin conservar). El tonelaje de los demás capítulos del arancel ha aumentado.

Con respecto al valor, destaca el incremento de las exportaciones en los capítulos 15 (grasas y aceites animales o vegetales), 2 (carnes y despojos comestibles), 3 (pescados, crustáceos, moluscos), 22 (bebidas), 16 (conservas de carne o pescado), 20 (conservas vegetales y zumos), 4 (leche, productos lácteos y huevos) y 7 (legumbres y hortalizas sin conservar), todos con aumentos superiores a 100 millones de euros. También se observa aumento de la exportación en los demás capítulos, excepto el 12 (semillas oleaginosas y plantas industriales), el 17 (azúcares y artículos de confitería), el 11 (productos de la molinería y malta), el 16 (cacao y sus preparaciones) y el 24 (tabaco y sus sucedáneos). Proporcionalmente, los productos con mayor aumento (superior al 10 por 100) en las exportaciones han sido los de los capítulos 5 (otros productos de origen animal), 15 (grasas y aceites animales o vegetales), 16 (conservas de carne o pescado), 4 (leche, productos lácteos y huevos), 1 (animales vivos), 6 (plantas y flores) y 3 (pescados, crustáceos y moluscos). Han registrado descensos cinco capítulos: el 12 (semillas oleaginosas y plantas industriales), el 17 (azúcares y artículos de confitería), el 11 (productos de la molinería y malta), el 24 (tabaco y sus sucedáneos) y el 8 (frutas y frutos sin conservar).

Las importaciones agroalimentarias (Cuadro 3) supusieron 35.877 millones de euros y 42.456.846 toneladas. En relación con la importación total española de bienes (301.870 millones de euros), el sector agroalimentario ha supuesto el 11,9 por 100 del valor total importado, muy similar (0,3 por 100 inferior) al porcentaje de 2016 (12,2 por 100).

Con respecto al año anterior, y en términos de valor, en 2017 se ha producido un aumento del 7,3 por 100 de las importaciones agroalimentarias (2.455 millones de euros), debido fundamentalmente a los capítulos 15 (grasas y aceites), 3 (pescados, crustáceos y moluscos), 16 (conservas de carne o pescado), 4 (leche, productos lácteos y huevos), 10 (cereales), 24 (tabaco y sus sucedáneos), 17 (azúcares y productos de confitería) y 2 (carnes y despojos comestibles), cada uno con un incremento superior a 100 millones de euros. En términos porcentuales, los mayores aumentos se han producido en los capítulos 14 (materias trenzables), 15 (grasas y aceites), 16 (conservas de carne o pescado), 17 (azúcares y productos de confitería), 1 (animales vivos) y 4 (leche, productos lácteos y huevos), todos con un incremento superior al 10 por 100 . Ha habido reducción de las importaciones, en ningún caso superior a 100 millones de euros, y además del avituallamiento, en los capítulos 18 (cacao y sus preparaciones), 11 (productos de la molinería y malta) y 22 (bebidas).

En cuanto al volumen, se ha producido una subida del 6,3 por 100. Destacan los capítulos 10 (cereales), 15 (grasas y aceites), 23 (residuos de la industria alimentaria), 17 (azúcares y $\triangleright$ 


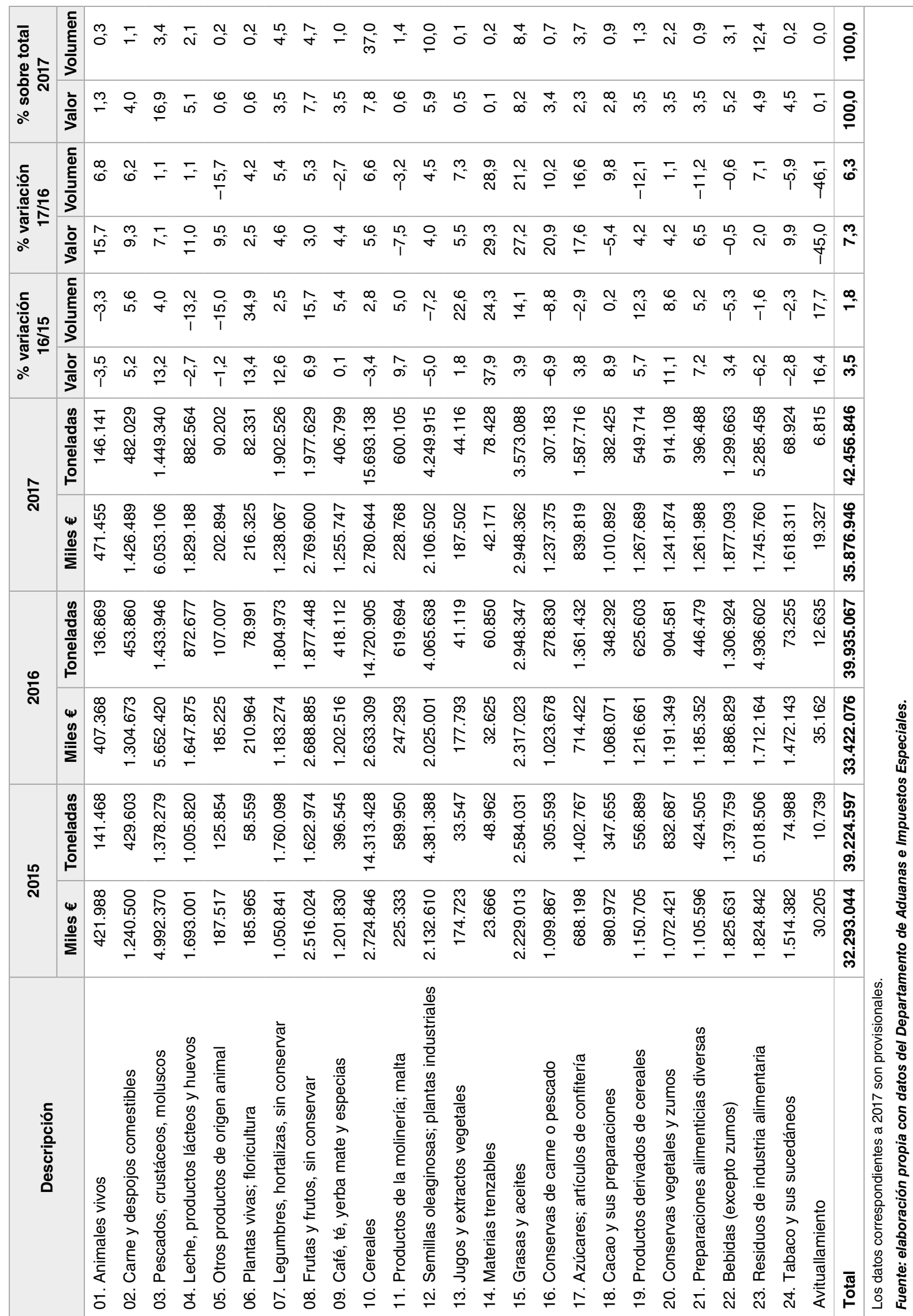


productos de confitería), 12 (residuos de la industria alimentaria y plantas industriales) y 8 (frutas y frutos sin conservar), cada uno con un incremento superior a 100.000 toneladas. En términos porcentuales, los mayores aumentos han tenido lugar en los capítulos 14 (materias trenzables), 15 (grasas y aceites), 17 (azúcares y productos de confitería) y 16 (conservas de carne o pescado), con variaciones superiores al 10 por 100. Entre las disminuciones de las importaciones, en ningún caso superiores a 100.000 toneladas, además del avituallamiento, se encuentran los capítulos 19 (productos derivados de cereales), 21 (preparaciones alimenticias diversas), 11 (productos de la molinería y malta), 5 (otros productos de origen animal), 9 (café, té, yerba mate y especias), 22 (bebidas) y 24 (tabaco y sus sucedáneos).

El esquema de nuestras importaciones es similar al de años anteriores. En volumen hay nueve capítulos que superan el millón de toneladas, igual que en 2016 y uno menos que en 2015. Estos son, por orden de importancia, los capítulos: 10 (cereales), 23 (residuos industria alimentaria), 12 (semillas oleaginosas y plantas industriales), 15 (grasas y aceites animales o vegetales), 8 (frutas y frutos sin conservar), 7 (legumbres y hortalizas sin conservar), 17 (azúcares, artículos confitería), 3 (pescados, crustáceos y moluscos) y 22 (bebidas). Todos ellos suponen el 87,2 por 100 del total de las importaciones. Como se ha indicado, el principal capítulo es el de cereales, del que se han importado 15,7 millones de toneladas (37 por 100 del total).

En cuanto al valor, hay diecisiete capítulos que han superado los 1.000 millones de euros, igual que en 2016 y uno más que en 2015. El más relevante es el capítulo 3 (pescados, crustáceos y moluscos) del que se han importado 6.053 millones de euros y representa el 16,9 por 100 del total.
Por orden de importancia, se trata de los capítulos 3 (pescados, crustáceos y moluscos), 15 (grasas y aceites animal o vegetales), 10 (cereales), 8 (frutas y frutos sin conservar), 12 (semillas oleaginosas y plantas industriales), 22 (bebidas), 4 (leche, productos lácteos y huevos), 23 (residuos de la industria alimentaria), 24 (tabaco y sus sucedáneos), 2 (carne y despojos comestibles), 19 (productos derivados de cereales), 21 (preparaciones alimenticias diversas), 9 (café, té, yerba mate y especias), 20 (conservas y zumos vegetales), 7 (hortalizas y legumbres), 16 (conservas de carne o de pescado) y 18 (cacao y sus preparaciones). Todos ellos suponen el 93,8 por 100 del total.

En todos los capítulos ha aumentado el valor de importación en 2017, salvo en los capítulos 18 (cacao y sus preparaciones), 11 (productos de la molinería y malta) y 22 (bebidas), además del avituallamiento.

\section{Distribución geográfica del comercio exterior agroalimentario}

\subsection{Exportaciones por destino}

Los principales destinatarios de las exportaciones españolas son los demás países de la Unión Europea (UE). En el Cuadro 4 y el Gráfico 2 se puede observar un aumento de nuestras exportaciones a la UE en valor (6 por 100) y en volumen (3,7 por 100), representando el 77,7 por 100 de nuestras exportaciones totales en volumen (77,1 por 100 en 2016) y del 73,2 por 100 en valor (73,5 por 100 en 2016).

Considerados de manera individual, nuestros principales mercados en la UE son: Francia (15,9 por 100 en valor y 18 por 100 en volumen), Alemania (11,5 por 100 en valor y 13,5 por 100 en volumen), Italia (11,1 por $\triangleright$ 


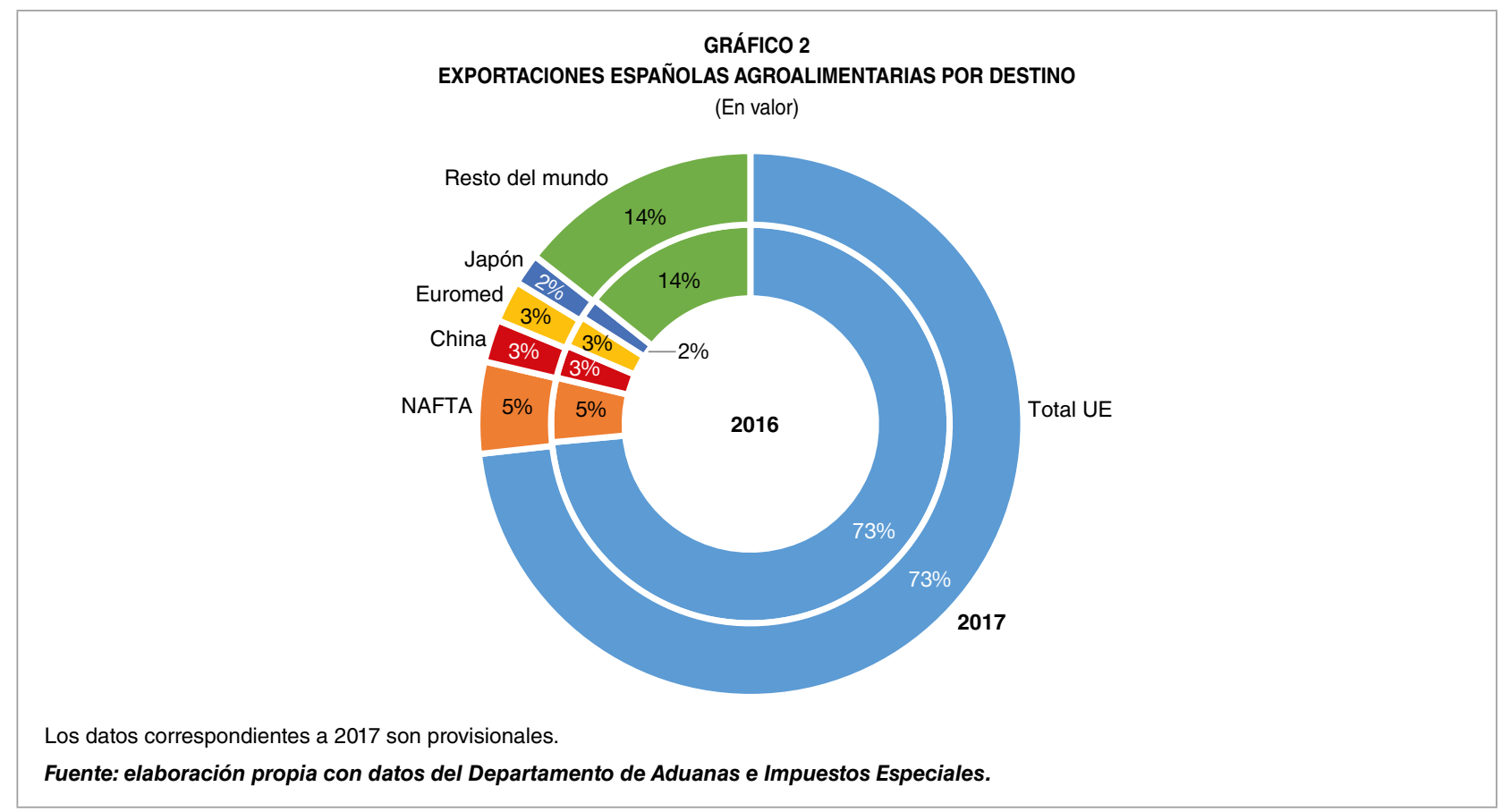

100 en valor y 8,2 por 100 en volumen), Portugal (9,3 por 100 en valor y 11,5 por 100 en volumen) y Reino Unido (8,1 por 100 en valor y en volumen). Estos cinco países suponen el 59,2 por 100 de la exportación

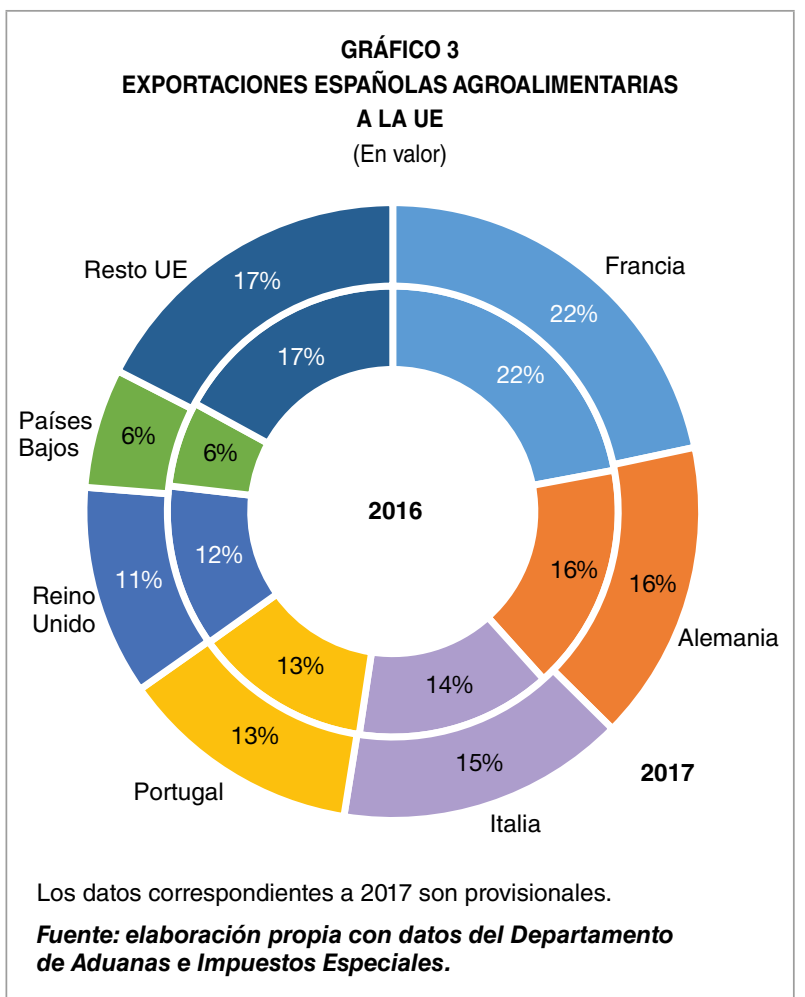

española en volumen y el 55,9 por 100 en valor (Gráfico 3).

Fuera de la Unión Europea, superan la cuota del 1 por 100 del volumen China (2,3 por 100), Emiratos Árabes Unidos (2,1 por 100), $\triangleright$

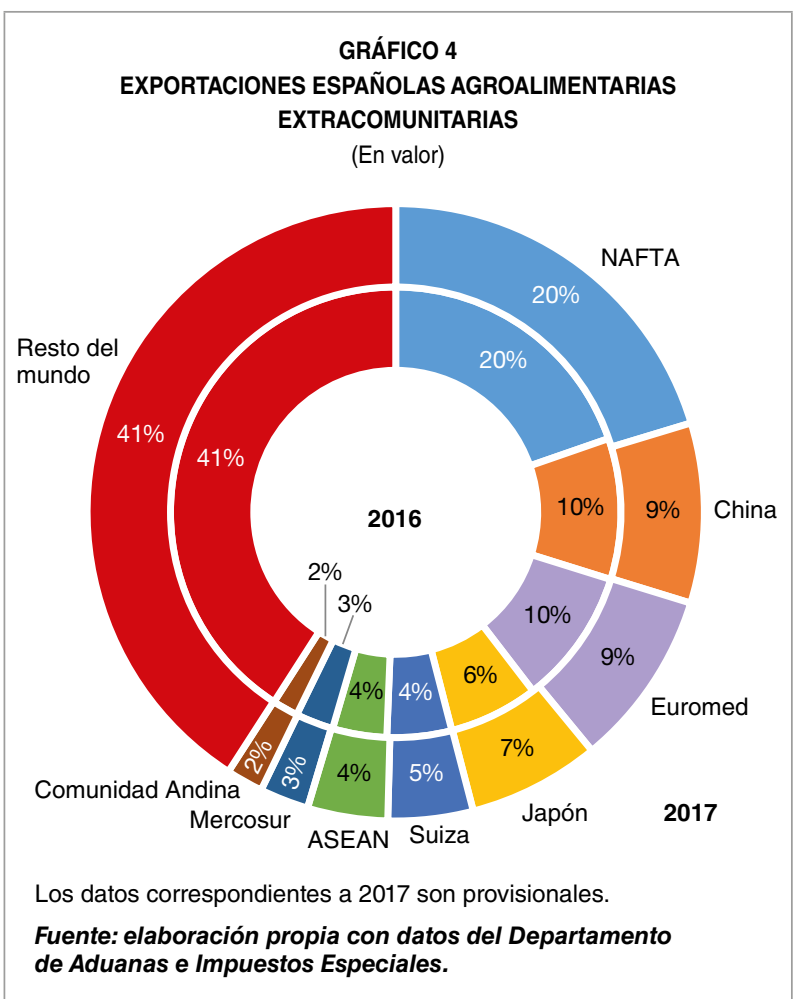




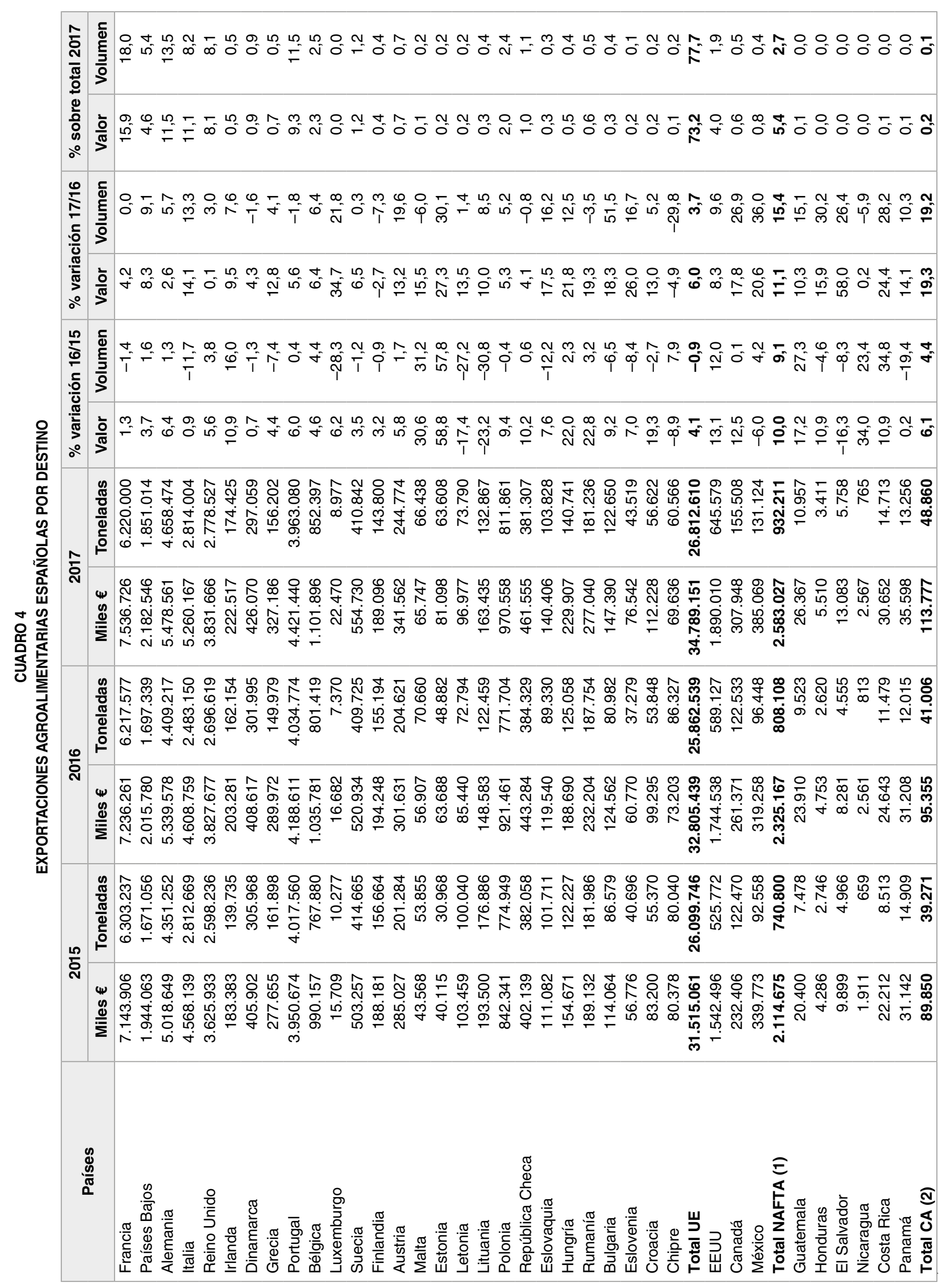




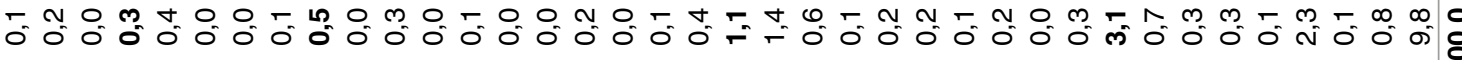

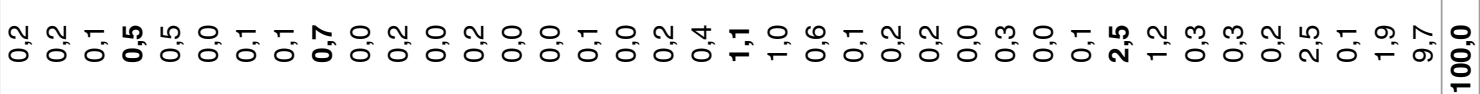

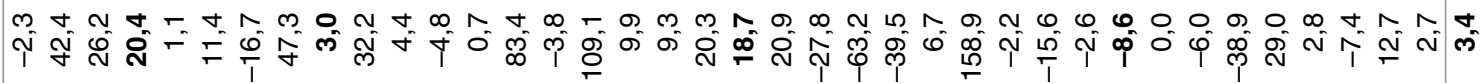

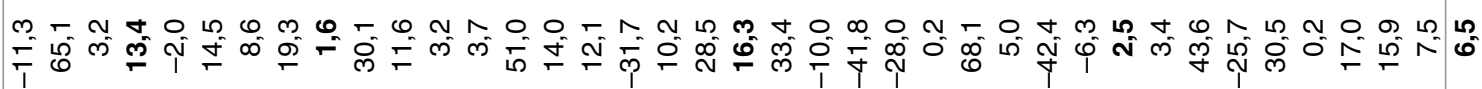
等 $\infty \forall$ ๖

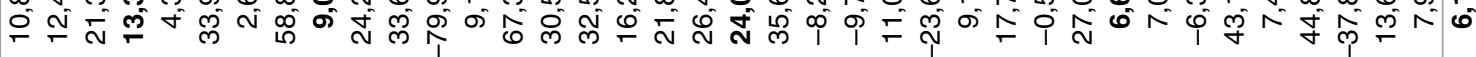
\&

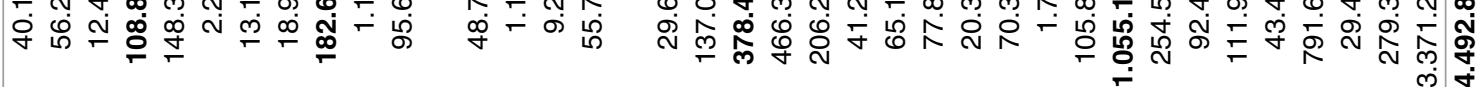

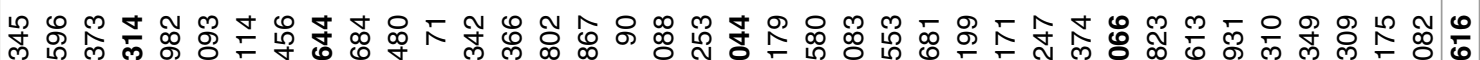

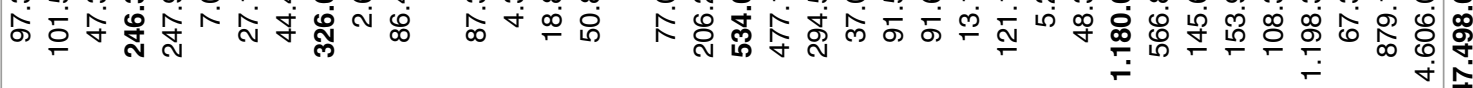

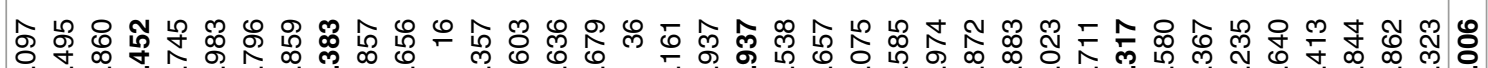

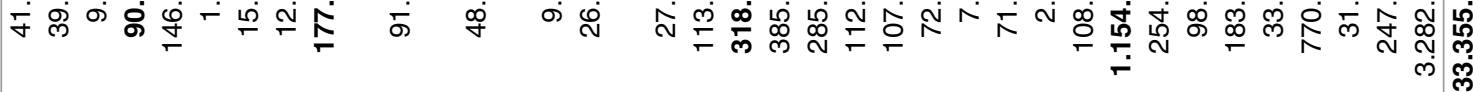

유유.

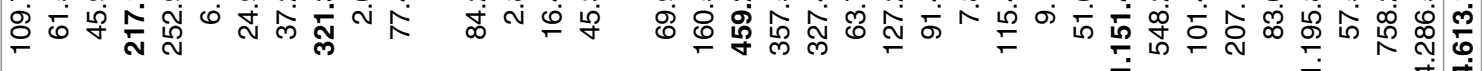

\&

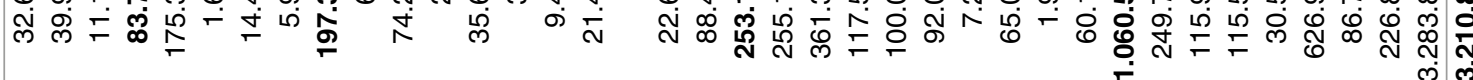

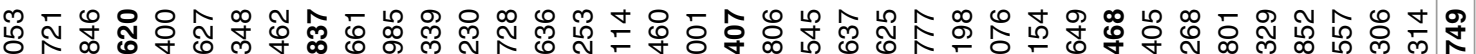

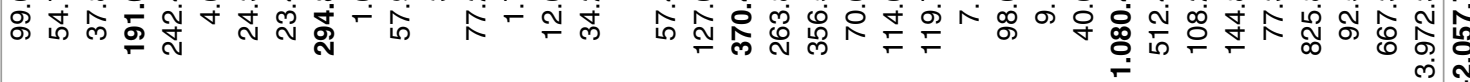

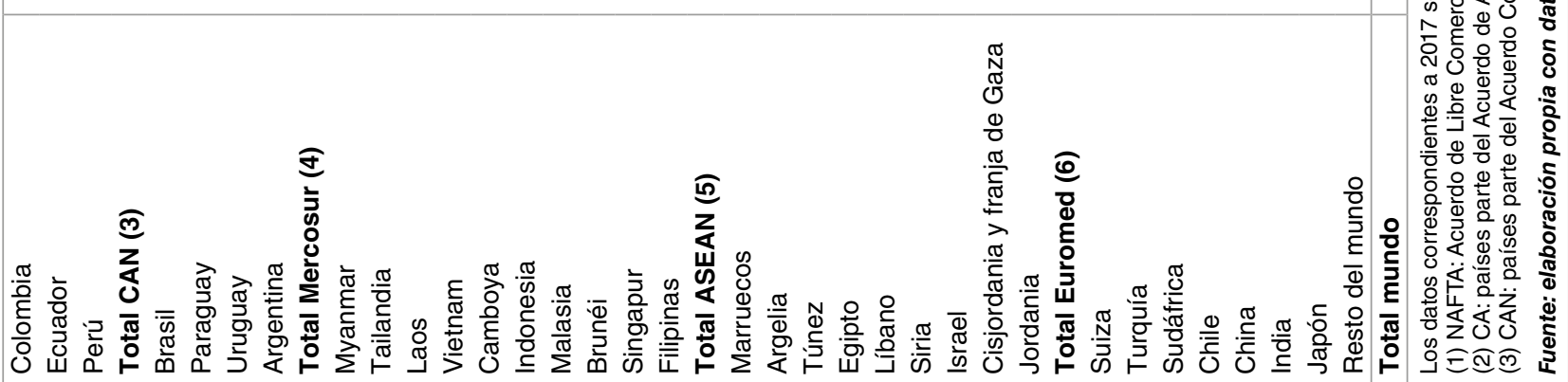


EEUU (1,9 por 100) y Marruecos (1,4 por 100). En valor, superan el 1 por 100 de las exportaciones totales: EEUU (4 por 100), China (2,5 por 100), Japón (1,9 por 100), Suiza (1,2 por 100) y Marruecos (1 por 100).

Por bloques de países, son mercados relevantes los Estados que forman parte del Acuerdo de Libre Comercio de América del Norte (NAFTA) y los países euromediterráneos (Gráfico 4). Las exportaciones españolas a NAFTA suponen el 2,7 por 100 del volumen y el 5,4 por 100 del valor total, y han aumentado con respecto a 2016 un 15,4 por 100 en volumen y un 11,1 por 100 en valor. Tres cuartas partes del valor de estas exportaciones tienen como destino EEUU.

Nuestras exportaciones a los países euromediterráneos representan el 3,1 por 100 en volumen y el 2,5 por 100 en valor, y han aumentado un 2,5 por 100 en valor, aunque en volumen se han reducido un 8,6 por 100 .

\subsection{Importaciones por origen}

Los principales proveedores de productos agroalimentarios (Cuadro 5 y Gráfico 5) son también los demás países de la UE. En términos porcentuales sobre el total de 2017 , representan en volumen el 49,3 por 100 (54 por 100 en 2016) y en valor, el 53,9 por 100 (55,5 por 100 en 2016). Al compararlos con las importaciones de 2016, y en términos porcentuales, aumentan en valor (4,3 por 100), si bien disminuyen en volumen (2,9 por 100).

Los principales proveedores europeos en términos de volumen son Francia (más de 7 millones de toneladas), Bulgaria (más de dos millones de toneladas), Portugal, Rumanía, Alemania (estos tres con más de 1,5 millones de toneladas) y Países Bajos (con más de un millón de toneladas). En términos de valor, los principales proveedores son Francia, Alemania, Países Bajos, Portugal, Italia y Reino Unido, todos ellos con importaciones superiores a 1.000 millones de euros, y suponen el 41,7 por 100 del valor total importado por España. Fuera de la UE, igualan o superan la cuota del 1 por 100 del volumen Ucrania (9,8 por 100), Brasil (11,8 por 100), Argentina (5,9 por 100), EEUU (4 por 100), Indonesia (3,7 por 100), Marruecos (1,4 por 100), Canadá (1,3 por 100) y Paraguay (1,2 por 100).

Por lo que respecta al valor, solo cuatro países superan el 5 por 100, uno menos que el año pasado: Francia (13,4 por 100), Alemania (8,3 por 100), Países Bajos (6,9 por 100) y Portugal (5,5 por 100) (Gráfico 6). Fuera de la UE, superan el 1 por 100 Brasil (4,6 por 100), EEUU (4 por 100, aunque en 2016 superaba el 5 por 100), Marruecos (3,9 por 100), Argentina (3,5 por 100), Indonesia (3 por 100), Ucrania (2,9 por 100), China (2,5 por 100), Ecuador (1,6 por 100), Perú (1,6 por 100), India (1,1 por $100)$, Vietnam (1 por 100) y Chile (1 por 100).

Por bloques, fuera de la UE, el siguiente grupo de países, por orden de importancia, es el Mercado Común del Sur (Mercosur) (Gráfico 7). Al igual que en 2016, Mercosur mantiene la segunda posición entre los principales proveedores. En términos porcentuales sobre el total de 2017, Mercosur representa el 19 por 100 en volumen (13,9 por 100 en 2016$)$ y el 8,8 por 100 en valor (8,2 por 100 en 2016). Las variaciones porcentuales respecto al año anterior indican un incremento en valor y en volumen (16,5 y 45,3 por 100 respectivamente). Brasil y Argentina continúan siendo los principales proveedores tanto en volumen (5 millones y de 2,5 millones de toneladas respectivamente) como en valor (1.641 millones y 1.271 millones de euros respectivamente). 


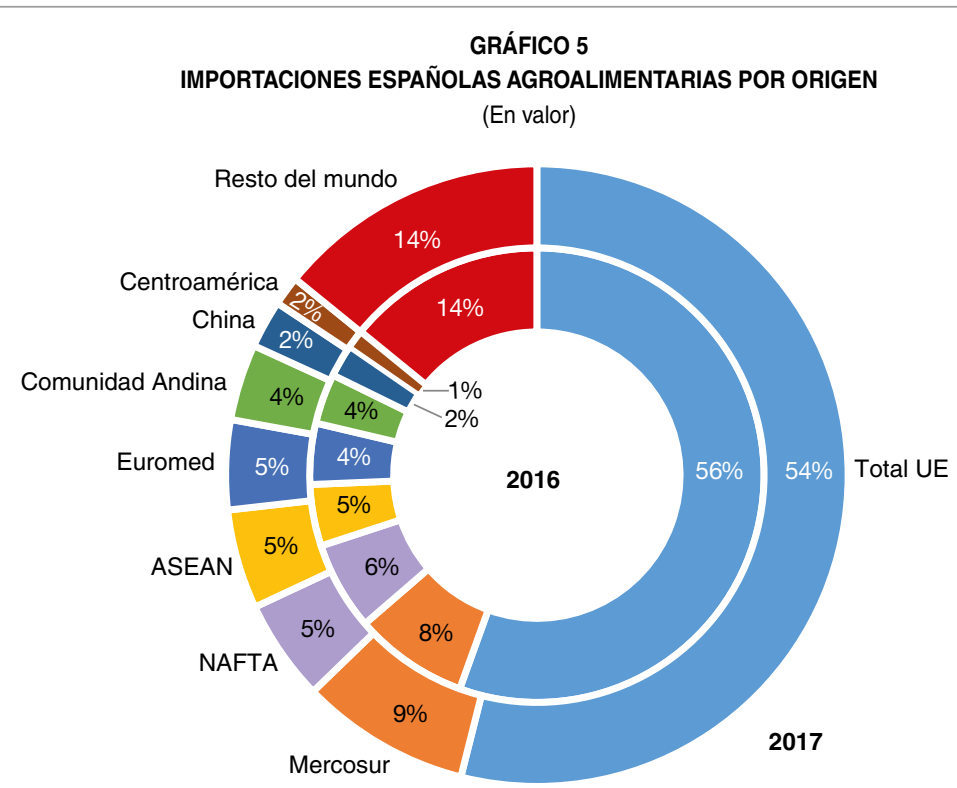

Los datos correspondientes a 2017 son provisionales.

Fuente: elaboración propia con datos del Departamento de Aduanas e Impuestos Especiales.

El tercer grupo de países proveedores es NAFTA, con el 5,6 por 100 del volumen y el 5,3 por 100 del valor total importado. Con respecto a 2016, las importaciones se han reducido ligeramente

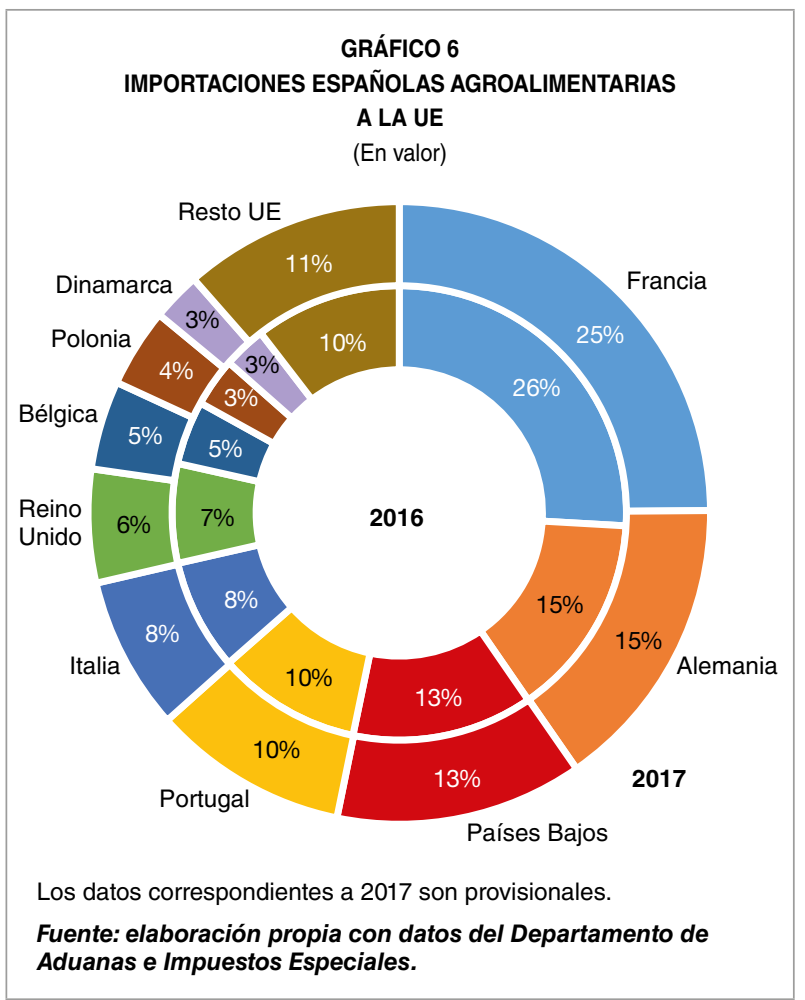

en volumen ( $-0,8$ por 100 en volumen) y de forma más acusada en valor (-10,3 por 100). Igual que en el caso de las exportaciones, alrededor de las tres cuartas partes vienen de EEUU.

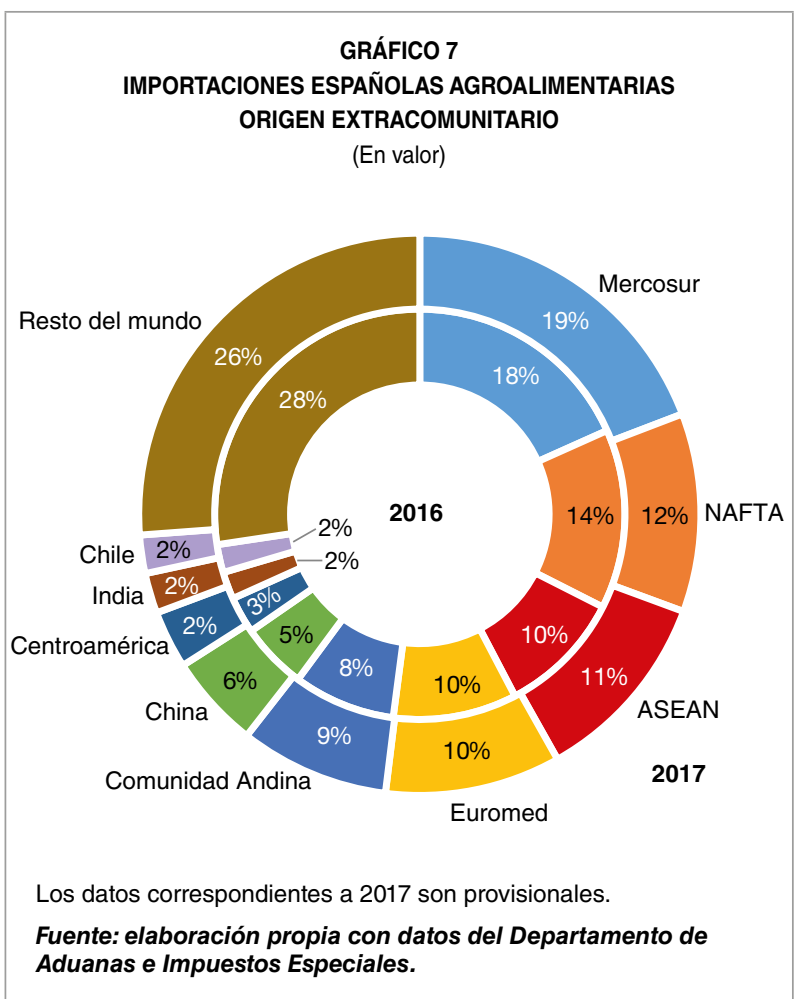




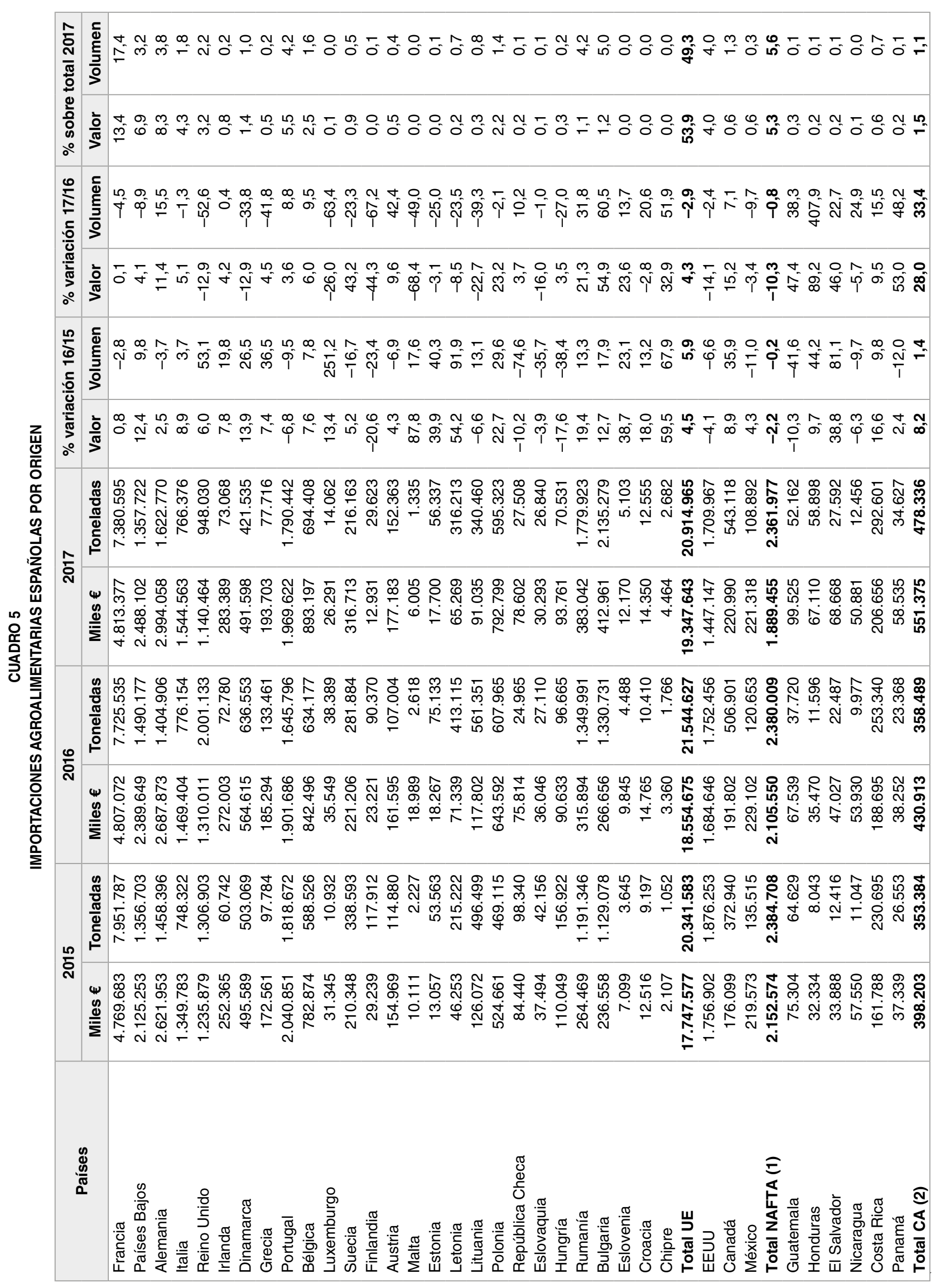




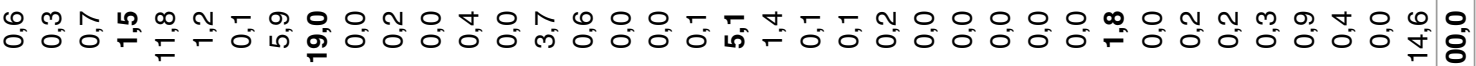

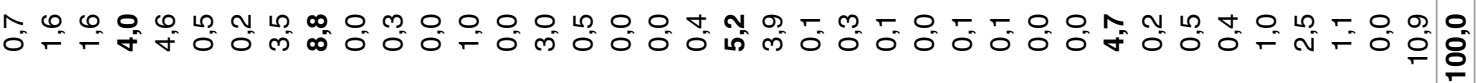

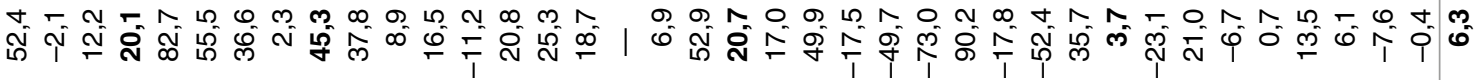

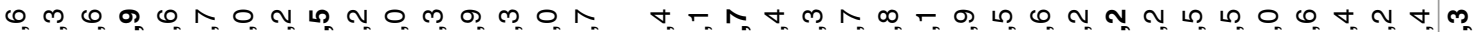

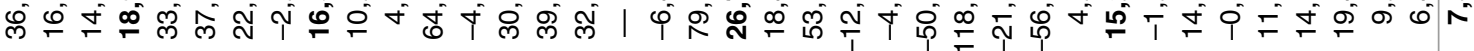

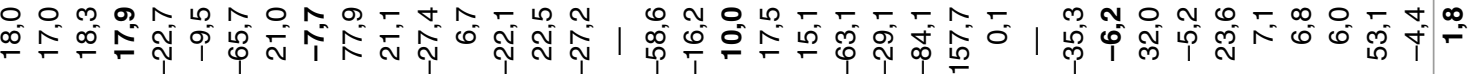

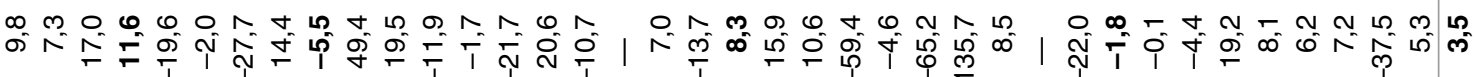

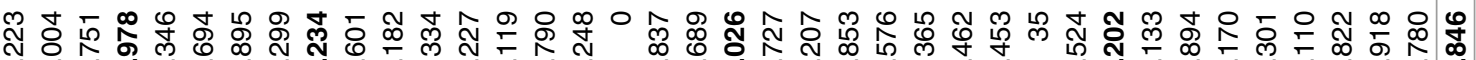

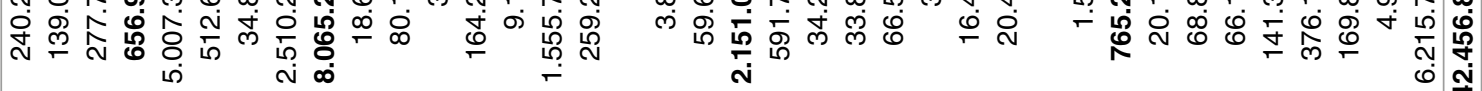

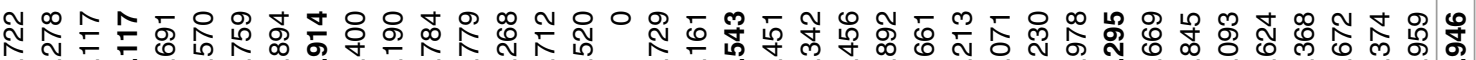

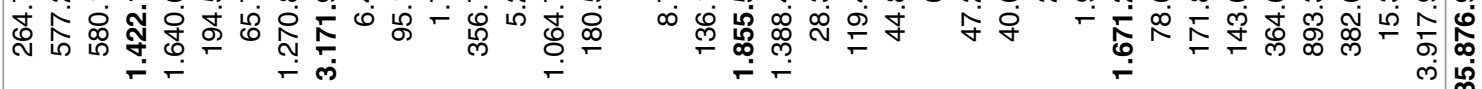

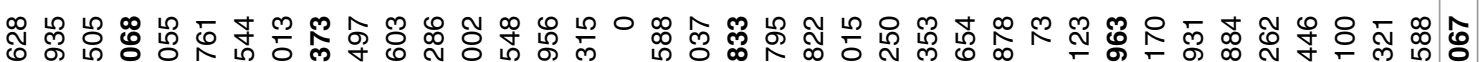

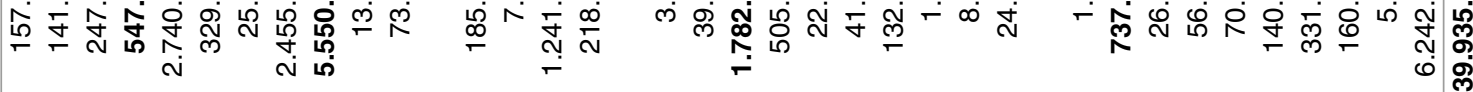

寺

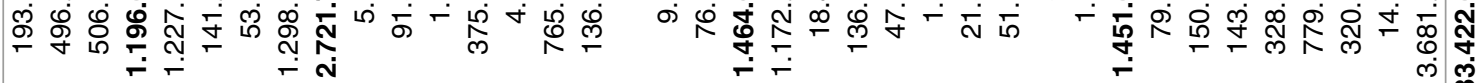
ल⿸户

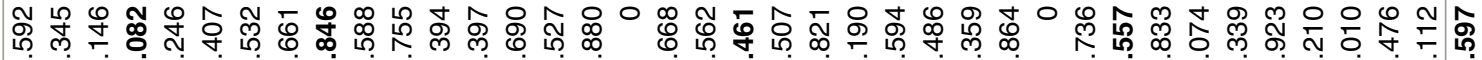

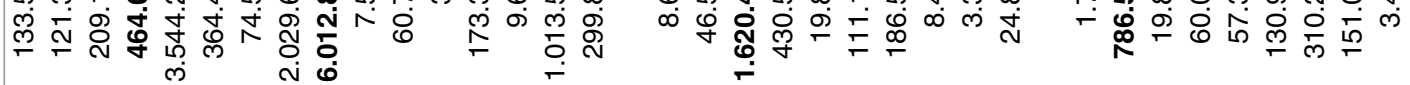

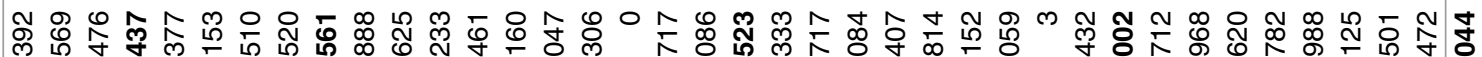

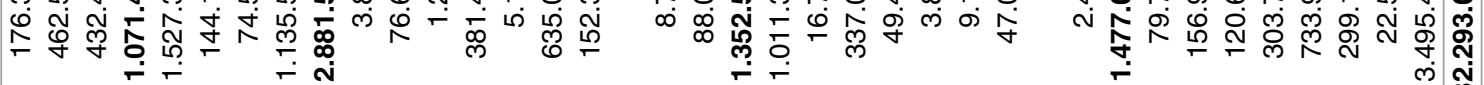


También tienen relevancia las importaciones de la Asociación de Naciones del Sudeste Asiático (ASEAN), con un 5,1 por 100 del volumen y un 5,2 por 100 del valor, y las de los países euromediterráneos (1,8 por 100 del volumen y 4,7 por 100 del valor). ASEAN ha aumentado intensamente sus exportaciones en 2017 (20,7 por 100 en volumen y 26,7 por 100 en valor), y en menor medida lo han hecho los países Euromed (3,7 por 100 en volumen y 15,2 por 100 en valor).

\section{Análisis sectorial del comercio exterior agroalimentario}

El análisis sectorial se presenta resumido en este artículo. La balanza comercial con el análisis sectorial completo se encuentra en http://www.comercio.gob.es/es-ES/comercio-exterior/informacion-sectorial/agroalimentarios/estadisticas/Paginas/estadisticas.aspx

El Cuadro 6 permite tener una visión de conjunto del comercio exterior por sectores.

CUADRO 6

BALANZA COMERCIAL AGROALIMENTARIA POR SECTORES

(Miles de euros)

\begin{tabular}{|c|c|c|c|c|c|c|c|c|}
\hline \multirow{2}{*}{ Descripción } & \multicolumn{3}{|c|}{2016} & \multicolumn{3}{|c|}{2017} & \multirow{2}{*}{\multicolumn{2}{|c|}{$\begin{array}{l}\text { \% variación 2017/2016 } \\
\text { Exportación Importación }\end{array}$}} \\
\hline & Exportación & Importación & Saldo & Exportación & Importación & Saldo & & \\
\hline Cárnicos & 6.538 .344 & 2.108 .137 & 4.430 .207 & 7.175 .531 & 2.294 .029 & 4.881 .502 & 9,7 & 8,8 \\
\hline Bovino & 863.603 & 917.734 & -54.131 & 982.532 & 1.004 .995 & -22.463 & 13,8 & 9,5 \\
\hline Ovino-caprino & 313.009 & 73.820 & 239.189 & 301.315 & 72.043 & 229.272 & $-3,7$ & $-2,4$ \\
\hline Porcino & 4.638 .162 & 469.007 & 4.169 .155 & 5.154 .562 & 517.238 & 4.637 .324 & 11,1 & 10,3 \\
\hline Aves y huevos & 596.881 & 578.688 & 18.193 & 601.506 & 619.946 & -18.440 & 0,8 & 7,1 \\
\hline Otros animales & 126.689 & 68.888 & 57.801 & 135.616 & 79.807 & 55.809 & 7,0 & 15,9 \\
\hline Lácteos & 968.371 & 1.501 .513 & -533.142 & 1.139 .438 & 1.668 .141 & -528.703 & 17,7 & 11,1 \\
\hline Pesca & 3.558 .113 & 6.352 .931 & -2.794 .818 & 3.988 .343 & 6.971 .022 & -2.982 .679 & 12,1 & 9,7 \\
\hline Cereales y prod. de la molinería & 616.672 & 2.880 .602 & -2.263 .930 & 622.340 & 3.009 .412 & -2.387 .072 & 0,9 & 4,5 \\
\hline Res. de ind. alimentaria y piensos & 963.732 & 1.712 .164 & -748.432 & 990.726 & 1.745 .760 & -755.034 & 2,8 & 2,0 \\
\hline Flores y plantas & 327.854 & 210.964 & 116.890 & 362.762 & 216.325 & 146.437 & 10,6 & 2,5 \\
\hline Hortalizas y legumbres & 5.876 .348 & 1.165 .547 & 4.710 .801 & 6.000 .002 & 1.221 .608 & 4.778 .394 & 2,1 & 4,8 \\
\hline Frutas & 8.242 .134 & 2.688 .885 & 5.553 .249 & 8.294 .215 & 2.769 .600 & 5.524 .615 & 0,6 & 3,0 \\
\hline Conservas vegetales & 2.599 .947 & 1.182 .756 & 1.417 .191 & 2.749 .304 & 1.238 .030 & 1.511 .274 & 5,7 & 4,7 \\
\hline Vinos, bebidas y vinagre & 4.019 .015 & 1.808 .391 & 2.210 .624 & 4.302 .448 & 1.788 .556 & 2.513 .892 & 7,1 & $-1,1$ \\
\hline Tabaco & 246.238 & 1.472 .143 & -1.225 .905 & 244.117 & 1.618 .311 & -1.374 .194 & $-0,9$ & 9,9 \\
\hline Grasas y aceites & 4.247.915 & 2.317 .023 & 1.930 .892 & 4.938 .407 & 2.948 .362 & 1.990 .045 & 16,3 & 27,2 \\
\hline S. oleaginosas, mandioca y forraje & 636.538 & 2.042 .728 & -1.406 .190 & 612.198 & 2.122 .961 & -1.510 .763 & $-3,8$ & 3,9 \\
\hline Café, té, cacao y azúcar & 938.268 & 2.120 .302 & -1.182 .034 & 951.294 & 2.242 .208 & -1.290 .914 & 1,4 & 5,7 \\
\hline Industrias agroalimentarias & 4.281 .416 & 3.602 .919 & 678.498 & 4.461 .859 & 3.758 .231 & 703.628 & 4,2 & 4,3 \\
\hline Otros productos & 552.287 & 2.519 .001 & -4.847 .316 & 665.632 & 264.390 & 401.242 & 20,5 & $-89,5$ \\
\hline Total & 44.613 .193 & 33.422 .076 & 11.191.117 & 47.498 .616 & 35.876 .946 & 11.621 .670 & 6,5 & 7,3 \\
\hline
\end{tabular}

